(C) Kozhevnikov A.N., Pozdeeva N.A., Proshchenko Ya.N., Konev M.A., Nikitin M.S., Prokopovich E.V. , Brianskaia A.I., Afonichev K.A., Novik G.A., 2019

DOI 10.18019/1028-4427-2019-25-4-460-467

\title{
Diagnostic criteria for elbow injury in children with juvenile arthritis
}

\author{
A.N. Kozhevnikov ${ }^{1,2}$, N.A. Pozdeeva ${ }^{1}$, Ya.N. Proshchenko ${ }^{1}$, M.A. Konev ${ }^{1}$, M.S. Nikitin ${ }^{1}$, \\ E.V. Prokopovich ${ }^{1}$, A.I. Brianskaia ${ }^{1}$, K.A. Afonichev ${ }^{1}$, G.A. Novik ${ }^{2}$ \\ ${ }^{1}$ The Turner Scientific and Research Institute for Children's Orthopedics, Saint Petersburg, Russian Federation, \\ ${ }^{2}$ St. Petersburg State Pediatric Medical University, St. Petersburg, Russian Federation
}

\begin{abstract}
Juvenile arthritis is a severe inflammatory disease of pediatric musculoskeletal system that leads to the development of contractures, early disability and loss of joint function. An isolated elbow injury in children with juvenile arthritis (JA) is a rare condition that is diagnosed at a late stage and has a poor prognosis. Early diagnosis using a variety of imaging modalities is vital for maintaining elbow function and decreasing disability rate in children. Objective To specify diagnostic methods and clinical and laboratory tests that allow visualization of JA-specific signs in pediatric elbow. Material and methods The retrospective study included 15 children who received treatment for chronic arthritis of the elbow joint. Clinical and instrumental findings, dynamics in articular syndrome and efficacy of antirheumatic therapy were evaluated. Results and discussion The study allowed us to reveal specific features of elbow injury in children with JA. 1. The onset associated with an injury to the upper limb and 'mute' laboratory tests were observed in more than $80 \%$ of the cases. 2. Clinical examination of patients with JA showed absence of morning stiffness and evident pain, dry synovitis and joint contracture in most of the cases. 3. Radiological evaluation exhibited early erosion of the subchondral bone at the articular surface of olecranon. 4. There was a slight monotherapeutic effect on elbow joint synovitis noted with NSAID use. 5. Diagnosis of pediatric chronic arthritis of the elbow joint suggests a complex approach to evaluation of clinical and instrumental findings and their dynamics taking into consideration age related specific anatomy of the elbow that can facilitate detection of the underlying cause of chronic arthritis.
\end{abstract}

Keywords: juvenile arthritis, elbow joint, monoarthritis, diagnosis

Juvenile idiopathic arthritis (JIA) is the most common chronic inflammatory disease of childhood involving musculoskeletal system and is an important cause of severe disability $[1,2,3]$. JIA is a broad term that describes a clinically heterogenous group of chronic inflammatory arthropathies of unknown cause. Oligoarticular juvenile idiopathic arthritis (also known as oligoarthritis) is marked by the occurrence of arthritis in four or fewer joints. This is a well studied type of arthropathy that rarely results in early arthrosis with timely treatment. Oligoarthritis is divided into subtypes depending on the course of the disease and the condition can be classified as persistent, extended or short term (abortive). A clinically obvious onset of the disease with asymmetric (less frequently symmetric or „diagonal“) involvement of the joints of the lower extremities (the hip being not common) is a classical instance of persistent oligoarthritis. This subset usually starts before six-eight years of age reaching a peak between the ages of two and four years and is more common in girls than boys. Sometimes oligoarthritis affects the elbow joint or one-two small joints of the hands or feet (total not more than five joints involved). Persistent oligoarthritis rarely presents persistent monoarticular JIA. Asymmetric oligoarthritis of the joints of the upper extremities is very rare and shoulder is difficult to diagnose $[4,5,6]$.

An increasing incidence of JIA among pediatric population, persistent functional limitations, early arthritic signs and high rate of diability are indicative of chronic arthritis of the elbow joint. The condition is one of chronic childhood arthropathies that may be difficult to diagnose even with a variety of diagnostic intrumentation tests that can be attributed to multiple nosological entities and nonspecific clinical manifestations of arthropathy. Moreover, absence of diagnistic criteria and distinctive subtypes of juvenile oligoarthritis exert an influence on terms of verification of elbow involvement in rheumatoid arthritis (ILAR 2001; the Edmonton revision, 2004) [7].

Objective To specify diagnostic methods and clinical and laboratory tests that allow visualization of JA-specific signs in pediatric elbow.

Kozhevnikov A.N., Pozdeeva N.A., Proshchenko Ya.N., Konev M.A., Nikitin M.S., Prokopovich E.V., Brianskaia A.I., Afonichev K.A., Novik G.A. Diagnostic criteria for elbow injury in children with juvenile arthritis. Genij Ortopedii, 2019, vol. 25, no 4, pp. 460-467. DOI 10.18019/1028-4427-2019-25-4-460-467. (In Russian) 


\section{MATERIAL AND METHODS}

The study was a retrospective analysis of dynamics in articular syndrome of 15 children with active chronic monoarthritis who received treatment at orthopaedic and rheumatoid department № 7 , the Turner Scientific and Research Institute for Children's Orthopedics, between 2011 and 2016. There were $93.3 \%$ female and $6.7 \%$ male patients aged 3 to 11 years (mean age, $5.8 \pm 2.5$ years). On admission, all children with chronic arthritis of the elbow joint were diagnosed with synovitis of unknown etiology. No clinical, instrumentation and laboratory findings could confirm posttraumatic and infection pathology. No signs of uveal activity were recorded throughout the whole period of observation. Children with the established cause of synovitis (tumor-like lesions of the synovial membrane, tumors of the articular portion of the bone) were excluded from the study.

Diagnostic findings and efficacy of therapy performed for the children were interpreted in combination with clinical and instrumentation data of the articular syndrome along with dynamics, functional tests and outcomes. Dynamics in the number of active joints and extent of functional limitations, inflammatory activity according to laboratory tests (ESR, C-reactive protein, white blood cell (WBC) count, platelet count, hemoglobilin level), immune status (antinuclear antibody (ANA), presence of the HLA-B27 antigene), signs of instrumentary assessment (erosion, pattern of changes in the synovial membrane, presence of exudate) and the efficacy of antirheumatoid therapy were evaluated.

"Disease activity levels of oligo-JIA" and JADAS10 scores adapted for pediatric rheumatoid practice (Beukelman et al., 2011; Horneff J. et al., 2012) were used to assess activity of the disease. Statistical data analysis were performed with standard programs Microsoft Excel. Empirical comparative analysis is presented in Tables. Absolute measurements are presented as a median and interquartile range (Me [25 \%; $75 \%]$ ) and relative data as percentages.

All patients provided informed written consent to participate in the study.

Stepwise antirheumatoid therapy included consecutive administration of nonsteroidal antiinflammatory drugs (NSAIDs), topical steroids (triamcinolone), cytotoxic drugs (methotrexate) and genetically engineered drugs to all children after diagnosis of JIA was established.

\section{RESULTS}

Analysis of isolated inflammatory arthropathy of the elbow joint showed that the onset of the disease occured on average 10 months ago [ $6 \div 14]$ by the time JIS was diagnosed. Onset was associated with acute injury to the elbow in $80 \%$ of cases. All children received complex therapy for posttraumatic condition with temporary immobilization of the elbow joint prior to the established diagnosis of JIA. Low activity of articular syndrome was observed in $80 \%(12 / 15)$ of children with JIA, positive ANA detected in $60 \%$
$(9 / 15)$ and presence of HLA-B27 antigen in two children (13.3\%) (Tables 1 and 2 ).

Thus, most of the patients had arthropathy of the elbow joint that was specified as "dry synovitis" and progressive joint contracture without signs of morning stiffness and pain. No inflammatory signs could be seen in the joints in the majority of cases with targeted ultrasound as the primary visualization method. Low diagnostic role of US and MRI scanning was caused by manifestations of "dry synovitis" (Fig. 1; Table 3).

Table 1

Clinical signs of the articular involvement of the elbow in children with JIA

\begin{tabular}{|l|c|}
\hline \multicolumn{1}{|c|}{ Clinical symptom } & Number of cases \\
\hline No complaints of joint pains, abs. (\%) & $13 / 15(86.7)$ \\
\hline Morning stiffness, abs. (\%) & $0 / 15(0)$ \\
\hline Combined contracture, abs. (\%) & $8 / 15(53.3)$ \\
\hline Flexion contracture, abs. (\%) & $7 / 15(46.7)$ \\
\hline Painful active movements, abs. (\%) & $2 / 15(13.3)$ \\
\hline Painful passive movements within accepted ROM, abs. (\%) & $2 / 15(13.3)$ \\
\hline Painful passive movements trying to overcome joint contracture, abs. (\%) & $15 / 15(100)$ \\
\hline Visible totally swollen joint, abs. (\%) & $0 / 15(0)$ \\
\hline Visible locally swollen joint, abs. (\%) & $3 / 15(20)$ \\
\hline Palpable bulging joint capsule on some areas, abs. (\%) & $8 / 15(53.3)$ \\
\hline Painful joint at palpation, abs. (\%) & $0 / 15(0)$ \\
\hline Local pain at palpation of brachioradial articulation and olecranon, abs. (\%) & $10 / 15(66.7)$ \\
\hline
\end{tabular}


Laboratory findings and activity of the disease in children with JIA

\begin{tabular}{|c|c|}
\hline Counts and levels & Frequency \\
\hline ESR (erythrocyte sedimantation rate) $\mathrm{mm} / \mathrm{hr}, \mathrm{Me}$ [RI $25 ; 75$ procentiles] & $7.6[3 ; 12]$ \\
\hline CRP (C-reactive protein) mg/L, Me [RI 25; 75 procentiles] & $1.9[0.8 ; 2,2]$ \\
\hline Hemoblobin, $\mathrm{g} / \mathrm{L}, \mathrm{Me}$ [RI 25; 75 procentiles] & $125.3[118 ; 134]$ \\
\hline WBC, $\times 109 / \mathrm{L}, \mathrm{Me}[$ ИР $25 ; 75$ procentiles] & $8.0[6.8 ; 10,6]$ \\
\hline Platelets, $\times 109 / \mathrm{L}$, Me [ИР $25 ; 75$ procentiles] & $378.1[324 ; 440]$ \\
\hline ANA (antinuclear antibody ) $\geqslant 1 / 160$, abs. (\%) & $9 / 15(60)$ \\
\hline HLA-b27 antigen, abs. (\%) & $2 / 15(13.3)$ \\
\hline Low activity of the disease (JADAS10 $0.6-2.7$ ), abs. (\%) & $12 / 15(80)$ \\
\hline Moderate activity of the disease ( JADAS10 $2.7-16.4$ ), abs. (\%) & $3 / 15(20)$ \\
\hline High activity of the disease ( JADAS10 > 16.4), abs. (\%) & $0(0)$ \\
\hline
\end{tabular}

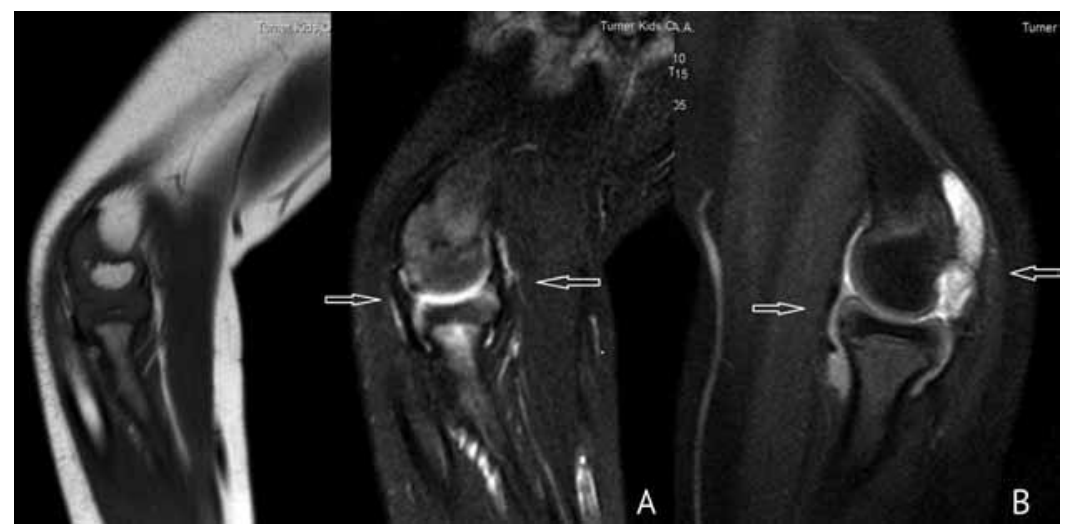

Fig. 1 MRI scan showing chronic arthritis of the elbow: $(\boldsymbol{A})$ dry synovitis (T1WI and T2WI), $(\boldsymbol{B})$ effusion and proliferative synovitis (T2WI)

Table 3

MRI and ultrasound findings of the articular involvement of the elbow in children with established diagnosis of JIA*

\begin{tabular}{|l|c|}
\hline \multicolumn{1}{|c|}{ Description } & Frequency \\
\hline echo - effusion synovitis, abs. (\%) & $2 / 15(13.3)$ \\
\hline echo - effusion proliferative synovitis, abs. (\%) & $3 / 15(20)$ \\
\hline no echo - structural inflammatory changes, abs. (\%) & $10 / 15(66.7)$ \\
\hline echo - erosive articular surfaces, abs. (\%) & $0 / 15(0)$ \\
\hline MRI - "obscure” non-erosive synovitis, abs. (\%) & $6 / 15(40)$ \\
\hline MRI - "obscure” erosive synovitis, abs. (\%) & $6 / 15(40)$ \\
\hline MRI - evident erosive synovitis, abs. (\%) & $3 / 15(20)$ \\
\hline
\end{tabular}

* as described by radiologist and doctor of functional diagnosis at the Turner Scientific and Research Institute for Children's Orthopedics

Currently, primary radiological diagnosis of inflammatory arthropathy of the elbow joint, like in most cases of classical JIA oligoarthritis must rely on modified model of sterotypical rheumatoid changes in the joint anatomy described by Steinbrocker $[8,9]$. In our series, radiological intention aimed at search of rheumatoid lesions resulted from absence of axial characteristics, disturbed integrity of anatomical structures, and also "hints" to the destruction of the joint being subject to inflammation (Table 4).

Consecutive analysis of the structure, optical density and articular and osseous contouring indicated to stereotypical radiological signs being characteristic of chronic inflammatory arthropathy in childhood. Juxta-articular (metaepiphyseal) osteoporosis, accelerated ossification of cartilaginous models of the distal and proximal humerus, and solidification of periarticular soft tissues were the only primary radiological manifestations that were responsible for the course of chronic arthritis of the elbow joint. Radioanatomical features of the elbow and common articular involvement with dry synovitis made radiological appearance of inflammation in the capsule and the surrounding soft tissues obscure (Fig. 2). These radiological manifestations were detected in all children at the early stage of the disease and were consistent with the first stage of radioanatomical changes observed in JIA. Changes 
in the synovium could not be a reference because echo-structural inflammatory changes could not be be visualized with dry synovitis (Table 3 ) [10, 11].

Deleterious radiological dynamics at the first stage included signs of accelerated growth (hypertrophy) of the capitulum of the humerus and the trochlea, olecranon and the radial head with primary projectional (nongenuine) signs of the narrow articular space and sclerotic subchondral bone (Fig. 3).

Signs of deformity seen as a typical prominence or denticulation of the subchondral bone at the trochlea notch of the ulna or the radial head at the radioulnar articulation indicated either to the start or active process of erosion and progression of the disease (stage II anatomical changes). Radiological signs of accelarated ossification of the cartilaginous models and the irregular epiphyseal asymmetry were more evident in younger children at onset and the fastigium of the disease. It should be noted this sort of changes is expected to occur in all the articular structures at arthritic process of different severity. Reaction of growth plates to chronic inflammation was undistinguished and non-specific and even absent somewhere.

Table 4

Radiological manifestations of articular involvement of the elbow in children with established diagnosis of JIA*

\begin{tabular}{|l|c|}
\hline \multicolumn{1}{|c|}{ Description } & Frequency \\
\hline Regional osteoporosis, abs. (\%) & $15 / 15(100)$ \\
\hline $\begin{array}{l}\text { Signs of accelerated ossification in cartilaginous models of epimetaphyses forming the } \\
\text { elbow joint, abs. (\%) }\end{array}$ & $15 / 15(100)$ \\
\hline Deformed articular configuration (erosion), abs. (\%) & $8 / 15(53.3)$ \\
\hline Deformed extra-articular contours, abs. (\%) & $1 / 15(6.7)$ \\
\hline Narrow articular space, abs. (\%) & $8 / 15(53.3)$ \\
\hline Signs of arthrosis and arthritis (described by radiologist), abs. (\%) & $8 / 15(53.3)$ \\
\hline
\end{tabular}

* as described by radiologist at the Turner Scientific and Research Institute for Children's Orthopedics

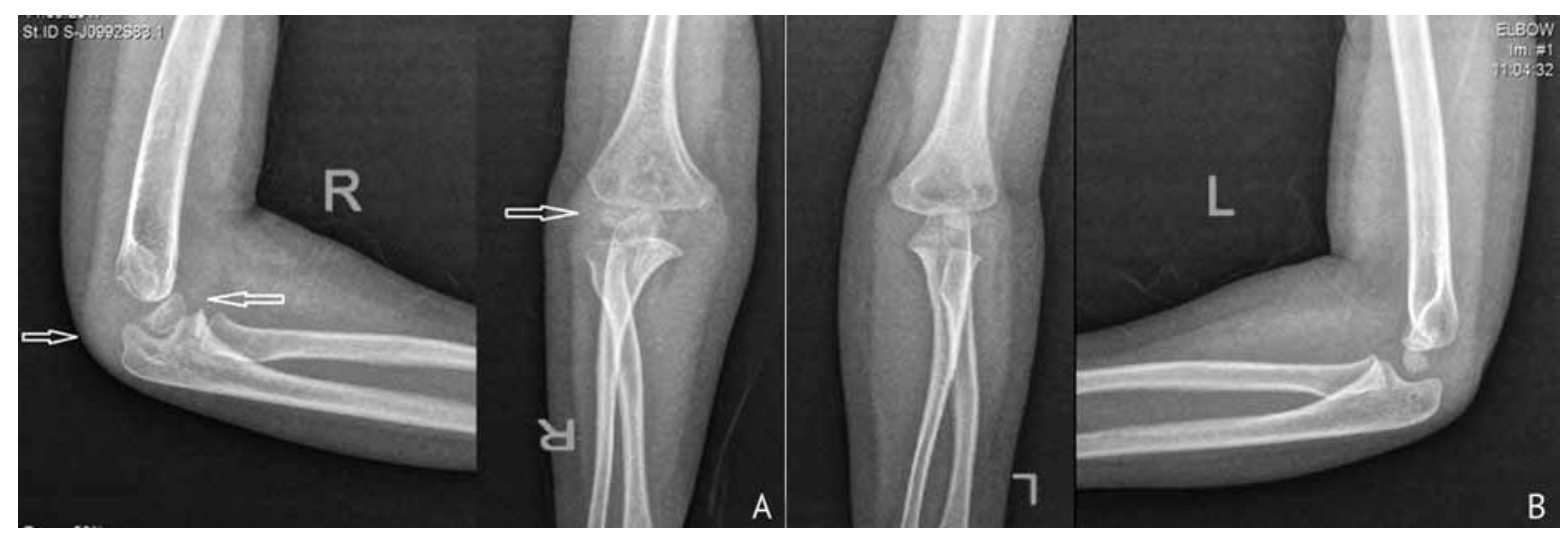

Fig. 2 The first stage of radioanatomical changes being characteristic of JIA of the right elbow joint $(\boldsymbol{A})$; radiographs of the elbow joint of the contralateral limb $(\boldsymbol{B})$

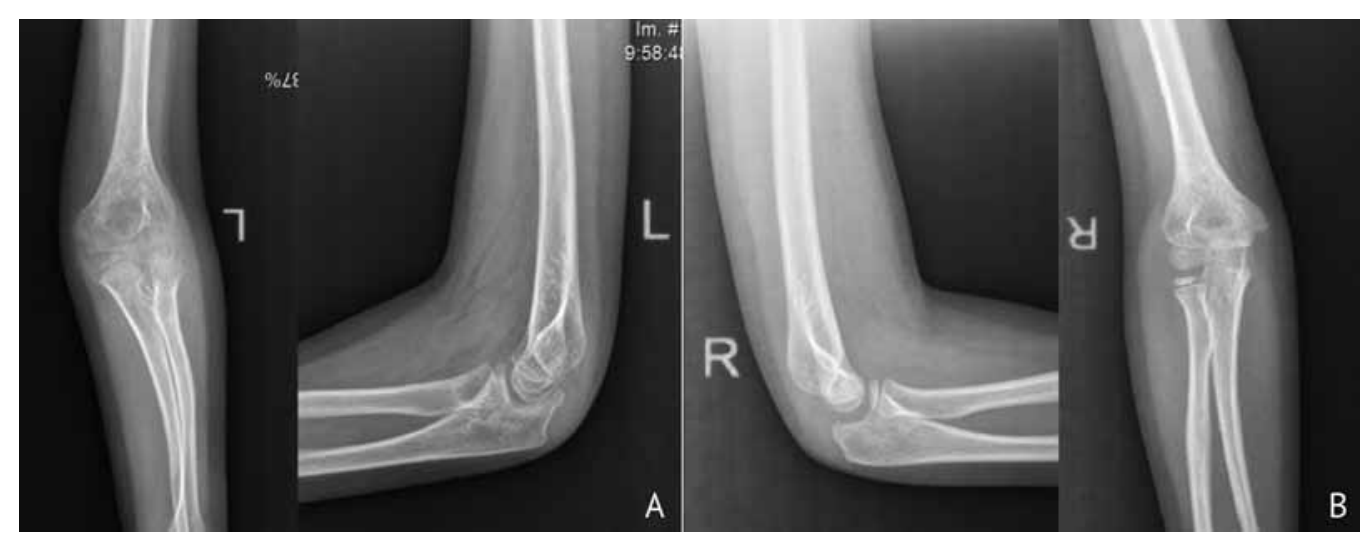

Fig. 3 Radioanatomical changes being typical for JIA of the elbow observed at the second stage $(\boldsymbol{A})$; radiographs of the elbow joint of the contralateral limb $(\boldsymbol{B})$ 
In our series, progression of articular inflammation was characterized by erosion and narrow articular space. Terms of articular erosion of the elbow joint were found to be different from that observed, for instance, in the knee. Erosion could be visualized at the end of the first year of JIA course in the elblow joint in absence of appropriate treatment. Early visualization of bony erosion at JIA of the elbow was likely to be indicative of delayed detection of the problem and long-term course of the condition along with narrow articular space. Genuine cartilaginous erosion was common in children with JIA and normally attended general decrease in thickness of cartilaginous matrix at the formation of arthrosis and arthritis (stage III anatomical changes, Fig. 4) [12].

MRI negative dynamics in articular syndrome was seen with new subchondral erosion observed in 4 children at 6-to-12-month observation (Table 5). Further observation showed that all children with JIA had erosion of the elbow joint without reference to a type of the disease course.
Mechanism of bone erosion in children is reported to be associated with osteoclast activation leading to the destruction of the subchonral endplate and a portion of the epiphyseal trabecular bone rather than genuine contacting nature. Genuine invasive or compression mechanism of elbow erosion was not found to be common in children [13]. Our series allowed detection of so called "hot spots of erosion" in the elbow joint that involved central and distal subchondral zones of the trochlea notch of the ulna whereas osseous and cartilaginous erosion of the capitulum of the humerus encountered in rare cases (Table 6, Fig. 5A, B) but resulted in erosion arthrosis-arthritis at a delayed perfiod. Radial zones of local osteosclerosis visualized along the contours of bone defect with concurrent regional osteoporosis on MR images indicated to „old“ erosion of the articular component. Olecranon and coronoid fossae appeared to be deformed in some cases with periosteal layers visualized at margical areas of capsule attachment. Non-specific ostitis of ulna, radius and humerus metadiaphyses were quite common (Fig. 5B).

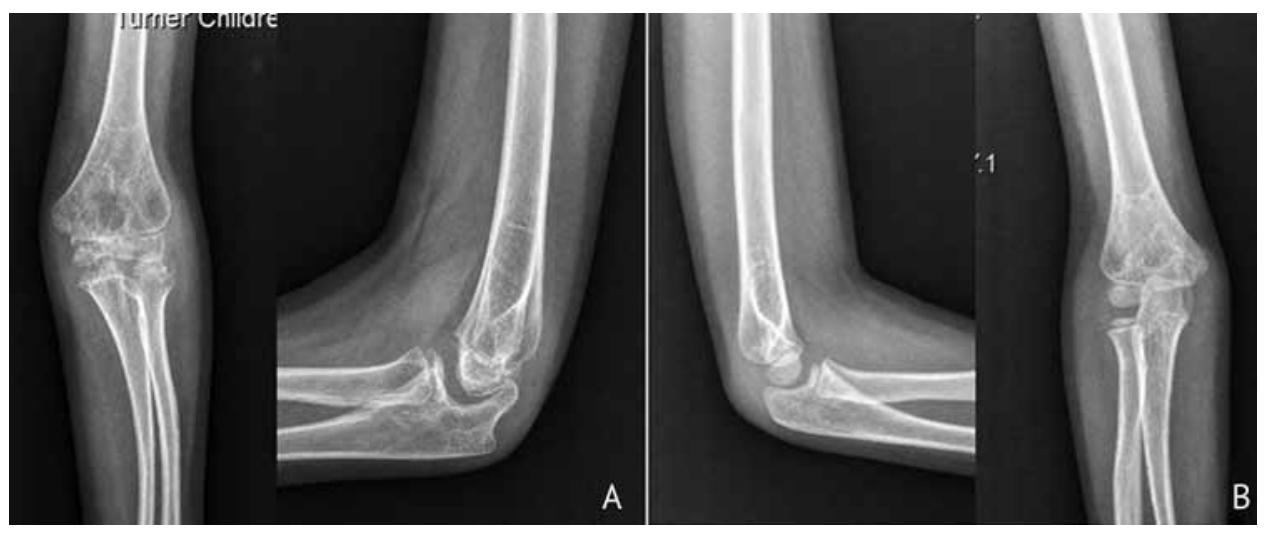

Fig. 4 Radioanatomical changes (arthrosis-arthritis) being typical for JIA of the left elbow observed at the third stage $(\boldsymbol{A})$; radiographs of the elbow joint of the contralateral limb $(\boldsymbol{B})$

Table 5

Radiological and MRI manifestations of articular involvement of the elbow joint in children with JIA at 6-to-12-month observation and therapy*

\begin{tabular}{|l|c|}
\hline \multicolumn{1}{|c|}{ Description } & Frequency \\
\hline Deformed contours of the articular surfaces (erosion), abs. (\%) & $12 / 15(80)$ \\
\hline Deformed contours of extra-articular zones, abs. (\%) & $3 / 15(20)$ \\
\hline Narrow articular space, abs. (\%) & $12 / 15(80)$ \\
\hline Destructive component, abs. (\%) & $0 / 15(0)$ \\
\hline Manifestations of arthrosis-arthritis as described by radiologist, abs. (\%) & $12 / 15(80)$ \\
\hline MR - "obscure" non-erosive synovitis, abs. (\%) & $3 / 15(20)$ \\
\hline MR - "obscure" erosive synovitis, abs. (\%) & $10 / 15(66.7)$ \\
\hline MR - evident non-erosive synovitis, abs. (\%) & $2 / 15(13.3)$ \\
\hline
\end{tabular}

* as described by radiologist at the Turner Scientific and Research Institute for Children’s Orthopedics 
Characteristics of elbow erosion in children with JIA*

\begin{tabular}{|l|c|}
\hline \multicolumn{1}{|c|}{ Description } & Frequency \\
\hline Erosion of brachioradial articulation seen in: & $3 / 15(20)$ \\
\hline cartilage, abs. (\%) & $2 / 15(13.3)$ \\
\hline superficially in the subchondral bone, abs. (\%) & $0 / 15(0)$ \\
\hline deep in the subchondral bone, abs. (\%) & $15 / 15(100)$ \\
\hline Erosion of the articular surface of olecranon seen in: & $15 / 15(100)$ \\
\hline cartilage, abs. (\%) & $2 / 15(13.3)$ \\
\hline superficial subchondral erosion of the trochlea notch, abs. (\%) & $4 / 15(26.7)$ \\
\hline deep subchondral erosion of the trochlea notch, abs. (\%) & $2 / 15(13.3)$ \\
\hline Erosion of the articular surface of the trochlea in the capitulum of the humerus seen in: \\
\hline cartilage, abs. (\%) & $0 / 15(0)$ \\
\hline superficial subchondral erosion, abs. (\%) & \\
\hline deep subchondral erosion, abs. (\%) & \\
\hline \%-results of our own MRI anlysis.
\end{tabular}

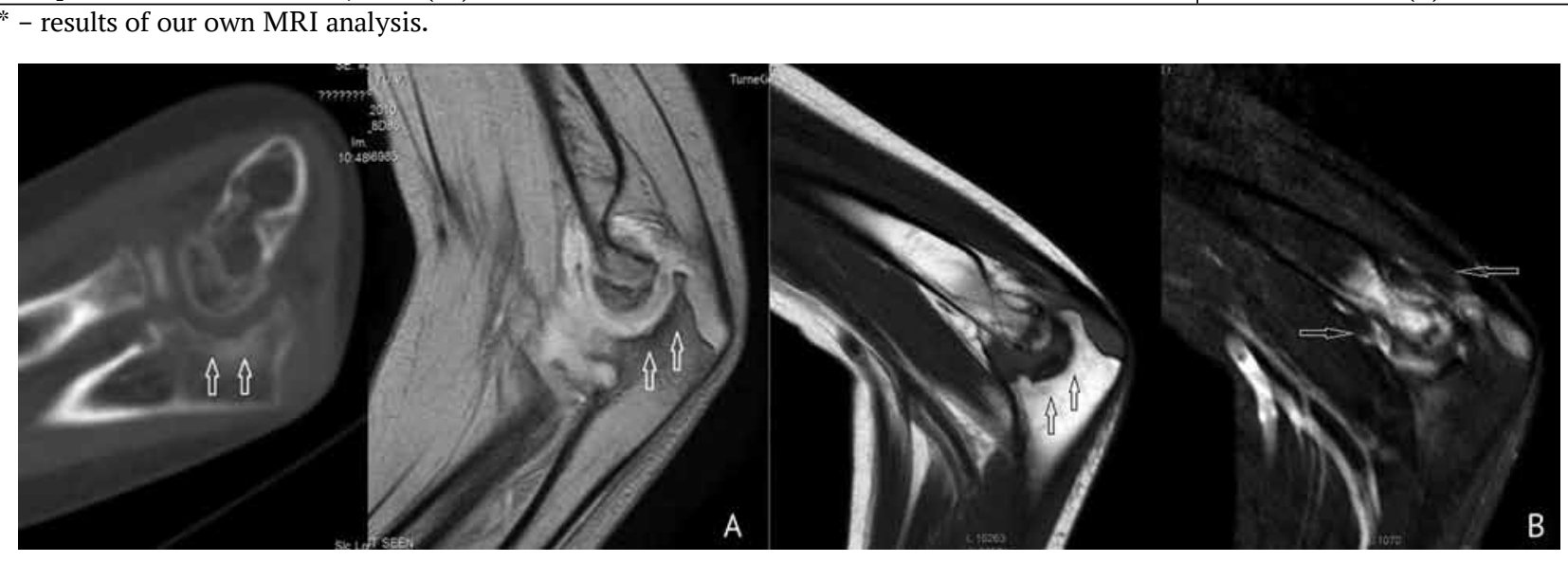

Fig. 5 Chronic arthritis of the elbow joints seen in: $(\boldsymbol{A})$ computed tomography scan (to the left) and MR T1WI showing erosive synovitis; $(\boldsymbol{B})$ MR T1W2 showing erosive synovitis and signs of nonspecific ostitis in the humerus metadiaphysis

Evaluation of the efficacy of therapy and dynamics in observation. Monotherapy with NSAIDs showed no significant clinical effect in all children. Positive dynamics was achieved with conventional antirheumatoid therapy that lasted for at least 6 months including intra-articular injection of triamcynolone $20-40 \mathrm{mg}+$ parenteral administration of methotrexate $15 \mathrm{mg} / \mathrm{m}^{2} /$ week combined with complex rehabilitation and correction of contractures. Genetically engineered biological drug anti-TNF (TNF blocker alpha) was initiated for two children. A complex of restorative treatment included a course of Artromot ${ }^{\circledR}$ robotic mechanotherapy, courses of multidirectional physiotherapy and serial casting for contractures were used in addition to daily exercise therapy. There were $33.3 \%(5 / 15)$ children with persistent oligoarthritis (2-5 joints); $40 \% \quad(6 / 15)$ with polyarthritis and $26.7 \%(4 / 15)$ had persistent isolated monoarthritis at a 2-year follow-up.

\section{DISCUSSION}

Current methodological analysis of joints based on standard imaging protocol includes US, MRI, CT and conventional radiography. US and MR imaging have become popular due to advanced level of diagnistic information, ultrasound volume visualization of the articular structures and the surrounding soft tissues, and minimal radiation exposure $[14,15]$. It should be noted that signs of chronic synovitis detected instrumentally are important but they are not the principle and the only signs being charactreistic of
JIA. In our series, visualization of typical reaction of metaphyseal bone forming the joint being subjected to chronic rheumatoid inflammation has been found to be a more sensitive and substantial diagnostic sign. The factor necessitates use of radiography as a priority in suspected joint inflammation, and primary radiological evaluation and physical examination would be helpful to determine an optimal, individual, consecutive algorithm for diagnosis of arthropathy $[16,17]$. 


\section{CONCLUSION}

We can suggest that chronic monoarthritis of the elbow joint is a rare entity characterizing onset of juvenile oligoarthritis. Inflammatory arthropathy can develop with low laboratory activity and absent symptoms of morning stiffness and mild pain. Dry synovitis and formation of the contracture were characteristic of JIA in most of cases. Instrumentary diagnosis of rheumatoid pathology of the elbow joint should primarily rely on sterotypical radiological signs of JIA. Ultrasound evaluation cannot be a tool that would deny rheumatoid pathology. Erosive process reflects an extent of aggressive course of arthritis and develops after one year of arthropathic progression. The articular surface of the olecranon is the most common site of early erosive changes. Monotherapy with NSAIDs cannot be the test to rule out JIA. Chronic arthritis of the elbow joint must be treated using a treat-to-target strategy.

Conflict of interests The authors declare that there is no conflict of interests regarding the publications of this article.

Funding No funding has been provided for the research.

\section{REFERENCES}

1. Alekseeva E.I., Bzarova T.M. Algoritm diagnostiki i lecheniia iuvenilnogo artrita [Algorithm of diagnosis and treatment of juvenile arthritis]. Voprosy Sovremennoi Pediatrii, 2010, vol. 9, no. 6, pp. 78-104. [in Russian]

2. Novik G.A., Abakumova L.N., Letenkova N.M., Slizovskii N.V., Slizovskaia N.N. Iuvenilnye artrity - opyt diagnostiki i lecheniia [Juvenile arthritis - the experience of diagnosis and treatment]. Lechashchii Vrach, 2008, no. 4, pp. 23-27. [in Russian]

3. Tsurikova N.A. Differentsialnaia diagnostika i lechenie oligoartritov u detei Synopsis Diss. kand. med. nauk [Differential diagnosis and treatment of oligoarthritis in children. Dr. med. sci. diss. synopsis]. Moscow, 2017, 28 p. [in Russian]

4. Kozhevnikov A.N., Pozdeeva N.A., Konev M.A., Selizov V.V., Moskalenko A.V., Afonichev K.A., Novik G.A. Iuvenilnyi artrit: osobennosti kliniko-instrumentalnoi kartiny i differentsialnoi diagnostiki [Juvenile arthritis: features of clinical-and-instrumental picture and differential diagnosis]. Lechashchii Vrach, 2016, no. 4, pp. 58-62. [in Russian]

5. Petty R.E., Southwood T.R., Manners P., Baum J., Glass D.N., Goldenberg J., He X., Maldonado-Cocco J., Orozco-Alcala J., Prieur A.M., Suarez-Almazor M.E., Woo P.; International League of Associations for Rheumatology. International League of Associations for Rheumatology classification of juvenile idiopathic arthritis: second revision, Edmonton, 2001. J. Rheumatol., 2004, vol. 31, no. 2, pp. 390-392.

6. Kim Y.D., Job A.V., Cho W. Differential diagnosis of juvenile idiopathic arthritis. J. Rheum. Dis., 2017, vol. 24, no. 3, pp. $131-137$. Available at: https://doi.org/10.4078/jrd.2017.24.3.131.

7. Marino A., Pagnini I., Savelli S., Moretti D., Simonini G., Cimaz R. Elbow monoarthritis: an atypical onset of juvenile idiopathic arthritis. Reumatismo, 2012, vol. 64, no. 3, pp. 175-179. DOI:10.4081/reumatismo.2012.175.

8. Smirnov A.V., Karateev D.E. Stadii rentgenologicheskikh izmenenii v sustavakh pri revmatoidnom artrite [Stages of X-ray changes in joints for rheumatoid arthritis]. Russkii Meditsinskii Zhurnal, 2014, no. 7, pp. 551-553. [in Russian]

9. Van Rossum M.A., Zwinderman A.H., Boers M., Dijkmans B.A., Van Soesbergen R.M., Fiselier T.J., Franssen M.J., Ten Cate R., Van Suijlekom-Smit L.W., Wulffraat N.M., Kuis W., Van Luijk W.H., Oostveen J.C., Dijkstra P.F.; Dutch Juvenile Idiopathic Arthritis Study Group. Radiologic features in juvenile idiopathic arthritis: a first step in the development of a standardized assessment method. Arthritis Rheum., 2003, vol. 48, no. 2, pp. 507-515. DOI: 10.1002/art.10783.

10.Dias B.L., Imamura E.U., Izumi A.P., Pinheiro L.V., Borigato E.V. Juvenile idiopathic arthritis with dry synovitis: clinical case and review of literature. Acta Reumatol. Port., 2009, vol. 34, no. 3, pp. 541-545.

11.De Somer L., Lambot K., Wouters C., Bader-Meunier B. Juvenile idiopathic arthritis with dry synovitis: clinical and imaging aspects in a cohort of 6 patients. Pediatr. Rheumatol. Online J., 2011, vol. 9, no. Suppl 1, P173. DOI: 10.1186/1546-0096-9-S1-P173.

12.Smirnov A.V. Differentsialnaia rentgenologicheskaia diagnostika izmenenii v sustavakh kistei i distalnykh otdelov stop pri revmaticheskikh zabolevaniiakh [Differential X-ray diagnosis of changes in the joints of hands and distal feet for rheumatic diseases]. Sovremennaia Revmatologiia, 2010, vol. 4, no. 4, pp. 83-88. [in Russian]

13.Schett G., Gravallese E. Bone erosion in rheumatoid arthritis: mechanisms, diagnosis and treatment. Nat. Rev. Rheumatol., 2012, vol. 8, no. 11, pp. 656-664. DOI:10.1038/nrrheum.2012.153.

14.Sheybani E.F., Khanna G., White A.J., Demertzis J.L. Imaging of juvenile idiopathic arthritis: a multimodality approach. Radiographics, 2013, vol. 33, no. 5, pp. 1253-1273. DOI: 10.1148/rg.335125178.

15.Ording Muller L.S., Humphries P., Rosendahl K. The joints in juvenile idiopathic arthritis. Insights Imaging, 2015, vol. 6, no. 3, pp. 275-284. DOI: 10.1007/s13244-015-0406-0. 
16.Kozhevnikov A.N., Pozdeeva N.A., Konev M.A., Maricheva O.N., Afonichev K.A., Novik G.A. Rentgenodiagnostika khronicheskogo oligoartrita u detei [X-ray diagnosis of chronic oligoarthritis in children]. Biulleten Sibirskoi Meditsiny, 2017, vol. 16, no. 3, pp. 224-234. [in Russian]

17.Selvaag A.M., Flatø B., Dale K., Lien G., Vinje O., Smerdel-Ramoya A., Førre Ø. Radiographic and clinical outcome in early juvenile rheumatoid arthritis and juvenile spondyloarthropathy: a 3-year prospective study. J. Rheumatol., 2006, vol. 33, no. 7, pp. 1382-1391.

Received: 04.09.2018

\section{Information about the authors:}

1.Aleksei N. Kozhevnikov, M.D., Ph.D., The Turner Scientific and Research Institute for Children's Orthopedics, Saint-Petersburg, Russian Federation, Saint-Petersburg State Pediatric Medical University, Saint-Petersburg, Russian Federation, ORCID iD 0000-0003-0509-6198, Email: Infant doc@mail.ru.

2. Nina A. Pozdeeva, M.D., Ph.D., The Turner Scientific and Research Institute for Children's Orthopedics, Saint-Petersburg, Russian Federation, ORCID iD 0000-0002-7324-3332,

Email: pozdeeva.nina@gmail.com

3. Yaroslav N. Proschenko, M.D., Ph.D., The Turner Scientific and Research Institute for Children's Orthopedics; Saint-Petersburg, Russian Federation, Email: yar2011@list.ru

4. Mikhail A. Konev, M.D., The Turner Scientific and Research Institute for Children's Orthopedics, Saint-Petersburg, Russian Federation, ORCID iD 0000-0002-4662-8069

5. Evgeniy V. Prokopovich, M.D., Ph.D., The Turner Scientific and Research Institute for Children's Orthopedics, Saint-Petersburg, Russian Federation 6. Maksim S. Nikitin, M.D.,

The Turner Scientific and Research Institute for Children's Orthopedics, Saint-Petersburg, Russian Federation 7. Anastasia I. Bryanskaya, M.D., Ph.D.,

The Turner Scientific and Research Institute for Children's Orthopedics, Saint-Petersburg, Russian Federation 8. Konstantin A. Afonichev, M.D., Ph.D.,

The Turner Scientific and Research Institute for Children's Orthopedics, Saint-Petersburg, Russian Federation, ORCID iD 0000-0002-6460-2567,

Email: afonichev@list.ru

9. Gennadiy A. Novik, M.D., Ph.D., Professor, Saint-Petersburg State Pediatric Medical University, Saint-Petersburg, Russian Federation, ORCID iD 0000-0002-7571-5460.

Email:ga_novik@mail.ru 